\title{
Therapeutic Evaluation of 2\% Tea Lotion in Comparison with $5 \%$ Zinc Sulfate Solution in the Treatment of Acne Rosacea
}

\author{
Khalifa E. Sharquie ${ }^{1 *}$, Adil A. Noaimi ${ }^{1}$, Sarmad A. Al-Hashimy ${ }^{2}$, Mazin M. Al-Salih ${ }^{3}$ \\ ${ }^{1}$ Scientific Council of Dermatology \& Venereology-Iraqi and Arab Board for Medical Specializations, Department of Dermatology \\ \& Venereology, College of Medicine, University of Baghdad, Baghdad, Iraq; ${ }^{2}$ Light Therapy Unit, Department of Dermatology \& \\ Venereology, Baghdad Teaching Hospital, Baghdad, Iraq; ${ }^{3}$ Department of Dermatology \& Venereology, Baghdad Teaching Hospital, \\ Baghdad, Iraq. \\ Email: “ksharquie@ymail.com, adilnoaimi@yahoo.com, sarmadaalhashimi@yahoo.com, adilalnuaimy@yahoo.com
}

Received September $28^{\text {th }}$, 2013; revised October $28^{\text {th }}, 2013$; accepted November $6^{\text {th }}, 2013$

Copyright (C) 2014 Khalifa E. Sharquie et al. This is an open access article distributed under the Creative Commons Attribution License, which permits unrestricted use, distribution, and reproduction in any medium, provided the original work is properly cited. In accordance of the Creative Commons Attribution License all Copyrights @ 2014 are reserved for SCIRP and the owner of the intellectual property Khalifa E. Sharquie et al. All Copyright (C) 2014 are guarded by law and by SCIRP as a guardian.

\section{ABSTRACT}

Background: There are many effective topical and systemic therapies for acne rosacea. Topical zinc sulfate and tea lotion have been used in treatment of acne vulgaris. Objectives: To evaluate effectiveness of $2 \%$ tea lotion in comparison with $5 \%$ zinc sulfate solution in the treatment of acne rosacea. Patients and Methods: This single, blinded, comparative therapeutic clinical trial was carried out in the Department of Dermatology-Baghdad Teaching Hospital from June 2006-December 2007. Twenty two patients with acne rosacea were divided into two groups and were instructed to apply the following lotions for two months, Group $A$ used $2 \%$ tea lotion twice daily while Group B used 5\% zinc sulfate solution twice daily. Patient with severe acne rosacea were excluded from the study. Clinical improvement was evaluated every 2 weeks by determination of the disease severity score (Sharquie's score) before and after treatment. Results: Eighteen patients with acne rosacea completed the study with their ages ranging from 26 - $70(40.5 \pm 10.9)$ years. For Group $A$ and Group $B$ were $39.7 \pm 8.2,41.2 \pm 13.1$ years respectively, with eight patients in Group A, ten patients in Group B. Five percent zinc sulfate solution was statistically significant in reducing the disease severity score in acne rosacea, while $2 \%$ tea lotion was beneficial but did not reach statistically significant level as zinc sulfate solution. Conclusion: Five percent zinc sulfate solution was a good alternative remedy to be used in patients with acnerosacea.

\section{KEYWORDS}

Acne Rosacea; Tea Lotion; Topical Zinc Sulfate Solution

\section{Introduction}

Although acne rosacea is a common skin problem but unfortunately its etiopathogenesis still not well established as many factors have been suggested including genetic predisposition, gastrointestinal factor, infections such as Demodex folliculorum [1]; normal skin flora [2]; HIV infection (AIDS) [3], drugs as steroids, food, alcohol [4], sunlight and psychological factor.

Most recently a role of Helicobacter pylori (H. pylori) of the compylobacter group which infects the gastric

\footnotetext{
${ }^{*}$ Corresponding author.
}

mucosa has been proposed. It is suggested that there is an etiological relationship between acne rosacea and $H$. pylori [5]. H. pylori have been extensively investigated and do not appear to be central to the etiology of acne rosacea [4].

There are many topical and systemic therapies of rosacea all of which might induce full recovery but unfortunately either relapse rate is high or there will be persistent erythema, these therapies include: avoidance of irritants, protection against sunlight [4], ,facial massage [4], diet, camouflage, topical antibiotics, topical metronida 
zole [4], topical retinoid [4], Azeliac acid, Tacrolimus [4], Permethrin, oral antibiotics [4], oral metronidazole [4], oral retinoids, antihypertensive drugs, spironolactone [6], dapsone, steroids [4] and surgical treatment [4].

Zinc is one of essential trace elements [7] that forms an integral part of several enzymes and cofactors which is an essential element in cell growth [8].

After application for 72 hours, percutaneous absorption of zinc sulfate results in increase in zinc concentration in whole skin and epidermis. The more zinc applied to the skin, the greater the increase in epidermal zinc level. Topical zinc ions traverse skin and can be found in dermis and blood. A recent study demonstrated that zinc concentration in skin could be increased eightfold by topical application of zinc sulfate but a concentration of $3 \%$ was optimal. Zinc oxide is extremely insoluble and would not be expected to be similarly active [9].

Zinc sulfate has been introduced into dermatology as effective therapy for many specific dermatoses: Two percent zinc sulfate solution was found to be effective as an intralesional therapy for cutaneous leishmaniasis and verruca vulgaris with cure rate $94.7 \%$, 98.2\% subsequently $[10,11]$. Also, topical solution $[10 \%]$ was effectively used for plane warts [12]. Recently zinc sulfate solution has shown to be effective in treatment of superficial fungal infection in $10 \%$ and $15 \%$ concentrations $[13,14]$. Oral zinc sulfate has been successfully tried in the treatment of cutaneous leishmaniasis, acne rosacea and viral warts $[15,16]$.

Tea contains many chemicals like tanin, the phenolic group of tannin (mainly catechine) that are responsible for its antibacterial effect, and it has been shown to be effective topically in the treatment of acne vulgaris and impetigo contagiosum as through its antibacterial activity $[17,18]$. Epigallcatechinsgallate of tea was reported to modulate the production and biological action of androgens and hormones. Modulation of androgenic activity may be useful for treatment of various hormones related abnormality such as baldness, acne and androgen dependent alopecia [19].

So, the objective of the present work is to evaluate effectiveness of $2 \%$ tea lotion in comparison with $5 \%$ zinc sulfate solution in the treatment of acnerosacea.

\section{Patients and Methods}

This single-blinded, comparative, therapeutic clinical study was conducted at the Department of Dermatology and Venereology-Baghdad Teaching Hospital between June 2006 to December 2007.

A total number of 22 patients (15 Females and 7 males) with female to male ratio 2.1:1 (probably because female seeking medical advice more than male for cosmetic reason) were enrolled in this study. Their ages ranged from 26 - 70 years with a mean \pm SD of $40.5 \pm 10.9$ years.

History was taken from each patient including: age, gender, social status, job, history of the disease itself, the age of onset, duration, complaint of the patient, family history of the same disease or any other skin diseases, drug history (topical and systemic), presence of other skin diseases, other systemic diseases such as hypertension, diabetes mellitus or others, involvement of other systems such as eye involvement, gastrointestinal problems. Exacerbating factors (sun exposure, heat and psychological factors etc.), and habits (smoking, alcohol).

The nature and target of this study were explained for each patient and formal consent was taken for each patient before starting the therapy, after full explanation about the nature of the disease, course, the procedure of treatment, follow up, prognosis and the need for pre and post treatment photographs by Sony-Digital, high sensitivity, 16.1 megapixels, $5 \times$ optical zoom camera in the same place with fixed illumination and distance. Also, ethical approval was given by the scientific committee of the Scientific Council of Dermatology and VenereologyIraqi Board for Medical Specializations.

Patients were instructed to stop any other medications at least one month before starting the therapy. Physical Examination of the patients and assessment of their disease was done according to the disease severity score (Sharquie's score) [16] which includes: severity of erythema, number of papules and pustules, telangectasia, and presence or absence of rhinophyma. The severity of erythema was determined according to a color chart (Figure 1, Table 1).

Patients with stage I and II rosacea, including those with eye involvement, were included in this trial. Patients with stage III rosacea and those with severe steroid-induced rosacea were excluded.

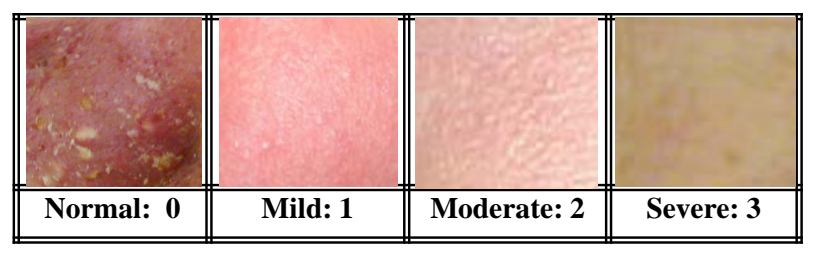

Figure 1. A color chart for the severity of erythema.

Table 1. Disease severity score.

\begin{tabular}{ccccc}
\hline Score & $\underline{\mathbf{0}}$ & $\underline{\mathbf{1}}$ & $\underline{\mathbf{2}}$ & $\underline{\mathbf{3}}$ \\
\hline Erythema & Absent & Mild & Moderate & Severe \\
Papule & 0 & $<5$ & $5-10$ & $>10$ \\
Pustule & 0 & $<5$ & $5-10$ & $>10$ \\
Telangiectasia & Absent & $<5$ & $5-10$ & $>10$ \\
Rhinophyma & $-\mathrm{ve}$ & & & $+\mathrm{ve}$ \\
\hline
\end{tabular}


Patients were divided into two groups:

1) Group A: Ten patients (7 Females and 3 males) were treated with $2 \%$ tea lotion. Their ages ranged from 33 - 53 years with a mean \pm SD of $39.7 \pm 8.2$ years. Each patient instructed to use the lotion topically twice daily for 2 months and clinical evaluation was done every 2 weeks. The assessment carried out by observing the severity of erythema and counting the number of the papules, pustules and telangiectasia and recording any side effects. Ophthalmological examination was done for all the patients by referring them to the ophthalmology clinic.

2) Group B: Twelve patients (8 Females and 4males) were used $5 \%$ zinc sulfate solution in a similar way of Group A. Their ages ranged from 26 - 70 years with a mean \pm SD of $41.2 \pm 13.1$ years. These cases were followed up for 2 months by observing the severity of erythema and counting the number of the papules, pustules, telangiectasia and mentioned any adverse effects. Ophthalmological examination was done for all the patients by referring them to the ophthalmology clinic.

The response of the patients to treatment was classified as:

1) Good response when the reduction in the mean score is more than $50 \%$,

2) Moderate response; when the reduction in the mean score is running from $10 \%-50 \%$.

3) No response; when the reduction of the mean score is less than $10 \%$.

Done by computer using EPI version 6. Calculation of mean and SD done for disease severity score. Comparison before and after treatment in each group was done by using paired t-test, and p-value less than 0.05 was considered as level of significance.

In this method, the tea leaves (apple brand mark) was added to boiled water ( $35 \mathrm{gm}$ of tea was mixed with 100 $\mathrm{ml}$ boiling hot distilled water), and then flame reduced to minimum and kept on low flame for 30 minutes (Iraqi method of decoction), then we let the tea extract to cool down, then we took $100 \mathrm{ml}$ of tea extract and $100 \mathrm{ml}$ of distilled water and we weigh them. The excess weight in the extracted tea is the amount of pure tea in tea lotion, for example if the difference is one gram between tea lotion and distilled water then the percent is $1 \%$, if the excess is two grams the concentration of tea will be $2 \%$ [17].

The $1 \%$ tea extract was boiled again until two thirds of water was evaporated, to reach 3\% tea extract concentration The $2 \%$ tea lotion $(100 \mathrm{ml})$ was prepared by adding $75 \mathrm{ml}$ tea extract and $25 \mathrm{ml}$ of ethanol (95\% purity) which is used as preservative.

Five percent $(\mathrm{W} / \mathrm{V})$ zinc sulfate solution is prepared by dissolving 5 grams of zinc sulfate crystals $\left(\mathrm{ZnSO}_{4} \cdot 7 \mathrm{H}_{2} \mathrm{O}\right.$ $=287.54$ from MERK, Franc) in $95 \mathrm{ml}$ of distilled water
$\mathrm{PH}=5.5$.

\section{Results}

Eighteen patients were completed the course of treatment in this work. Eight patients in Group A, 5 (62.5\%) females and 3 (37.5\%) males, 10 patients in Group B, 8 (80\%) females and $2(20 \%)$ males, $4(18.1 \%)$ patients did not complete the treatment and considered defaulter for unknown reason(2 from Group A and 2 from Group

B).

The duration of the disease ranged between 1 month and 20 years. Positive family history was found in 3 (13.6\%) patients.

Eye involvement occurred in 4 (18\%) patients: in the form of blepharitis in 3 patients, and conjunctivitis in one patient.

Gastrointestinal problems were found in one (4.5\%) patient in the form of gastritis.

The presenting symptoms of the patients were: erythema in 14 (63.6\%) patients, itching 13 (59\%), burning $11(50 \%)$ and only 1 (4.5\%) patient was asymptomatic and most patients had more than one complaint.

The sites of the lesions were: in the nose 15 (68.1\%) patients, cheek 13 (59\%), forehead 8 (36.3\%) patients and chin 3 (13.6\%) and most patients have more than one site.

Systemic diseases were found in: 6 (27.1\%) patients, 4 (18.1\%) of them have hypertension and 2 (9\%) had diabetes mellitus. Two (9\%) patients were alcoholic and 1 (4.5\%) patient was smoker.

The aggravating factors of the disease were mainly: sun 19 (86.3\%) patients, heat 17 (77.2\%), psychological stress 15 (68.1\%) and most patients have more than one aggravating factor.

\section{Clinical Results}

\section{Group A (Tea lotion):}

1) Evaluation of patient's response to treatment.

Three (37.5\%) patients showed no response while two (25\%) patients showed moderate response and three (37.5\%) patients had good response.

2) The assessment of mean \pm SD of disease severity score (Sharquie's score) before and after treatment was as follow:

The score was ranged before treatment between 4 - 9 with a mean \pm SD of $6.1 \pm 1.8$ that reduced to $4.2 \pm 2.6$ after treatment. This reduction was statistically not significant $(\mathrm{P}=0.1)$ (Table 2).

No important side effects were reported apart from burning sensation in one (12.5\%) patient and itching in another one $(12.5 \%)$ patient in the early course of treatments which were reduced with subsequent treatment. 


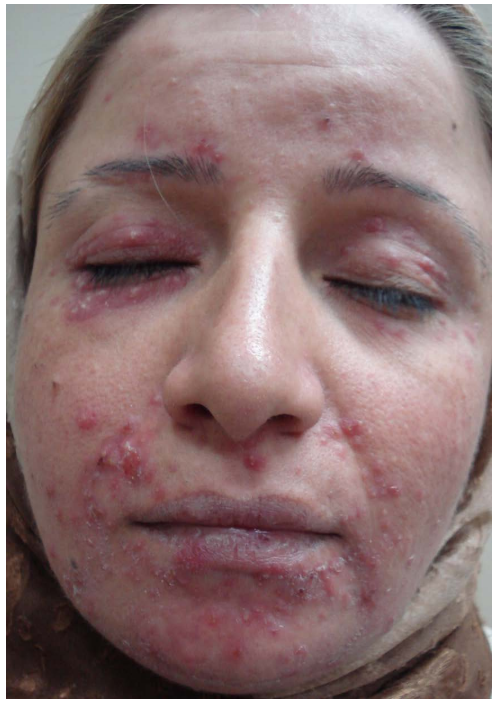

(a)

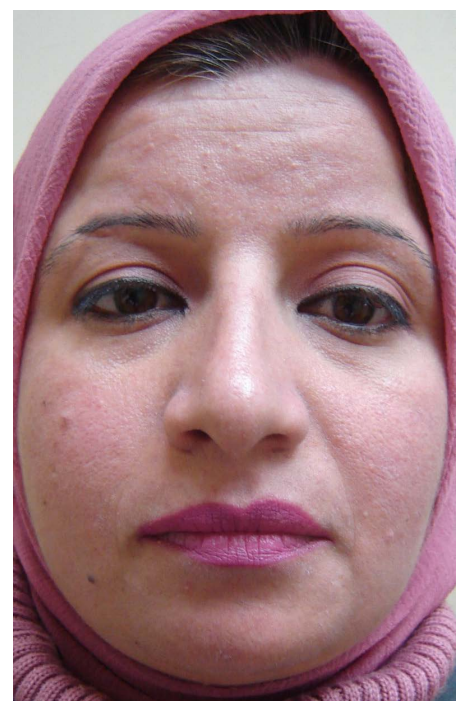

(b)

Figure 2. (a) Thirty five years old female with acne rosacea; (b) 35 years old female with acne rosacea after 2 months treatment with zinc sulfate solution.

Table 2. Mean \pm SD of disease severity score (Sharquie's score) before and after therapy for both groups.

\begin{tabular}{ccc}
\hline Group & $\mathbf{0}$ & 8 weeks \\
\hline & $\bar{X} \pm S D$ & $\bar{X} \pm S D$ \\
Group A & $6.1 \pm 1.8$ & $4.2 \pm 2.6$ \\
Significance & t-test 2.6, & $\mathbf{P}=\mathbf{0 . 1}$ \\
Group B & $7.4 \pm 1.9$ & $2.9 \pm \mathbf{1 . 9}$ \\
Significance & t-test 26.5, & $\mathbf{P}=\mathbf{0 . 0 0 0 0 3}$ \\
\hline
\end{tabular}

\section{Group B (Zinc sulfate solution):}

1) Evaluation of patient's response to treatment.

Zero (0\%) patients showed no response while 4 (40\%) patients showed moderate response and $6(60 \%)$ patients had good response.

2) The assessment of mean \pm SD of disease severity score (Sharquie'sscore) before and after treatment was as follow:

The score was ranged before treatment between 5 - 11 with a mean \pm SD of $7.4 \pm 1.9$ that reduced to $2.9 \pm 1.9$ after treatment. This reduction was statistically significant $(p=0.00003)$ (Table 2, Figure 2).

The papules and pustules showed a significant decrease in their numbers one month after starting treatment with zinc sulfate. Erythema was also reduced, but it needed longer time to show a significant response (becomes statistically significant after the second month of treatment). There was no significant effect of zinc sulfate on telangiectasia.

No important side effects were reported apart from burning sensation in 2 (20\%) patients and itching in 1
(10\%) patient in the early course of treatments which were reduced with subsequent treatment and not needed for cessation of therapy.

\section{Discussion}

The etiology of acne rosacea is still not well known and it seems that rosacea may have a multifactorial etiology [1-5]. Many medications have been used to control the activity of the disease including topical and systemic therapies, and these drugs might have side effects and cannot be tolerated by the patients for long term therapy $[4,5]$. Therefore, the present work aims to find simple and cost effective therapy to control the disease.

The present study confirmed that $5 \%$ zinc solution was effective in the clearance of the rash of rosacea while $2 \%$ tea lotion was much inferior in its effectiveness when compared with $5 \%$ zinc sulfate solution. These findings had been similarly noticed in the treatment of acne vulgaris but $2 \%$ tea lotion was more effective than $5 \%$ zinc solution [20].

The mechanisms of action of zinc sulfate solution is not fully clear, it might be due to enhancing the immunity through its immunomodulatory effect [20], Antimicrobial activity [10,11,13,15,21], anti-inflammatory activity [22], antioxidant action [23] and sun protection effect [24].

Five percent topical zinc sulfate solution has been shown also effective in treatment of acne vulgaris [20].

The mechanisms of action of tea lotion in rosacea is not fully understood, but it may be due to antibacterial activity against normal skin flora which might behave abnormally in rosacea patients due to higher facial skin 
temperature [5], skin protection effect against UVB-induced inflammatory responses [25,26], antioxidant, antiinflammatory effects $[25,26]$ and immune modulating action [27].

The 2\% tea lotion showed no side effects. To increase the effectiveness of $2 \%$ tea lotion we recommend further studies using $5 \%$ tea lotion as topical therapy with higher number of patients.

The effect of zinc sulfate solution on the papules and pustules became statistically significant one month after starting therapy.

These results are comparable to systemic azithromycin and metronidazole that are used to treat rosacea and results in significant improvement of the papules and pustules that continue 4 weeks after treatment [28]. While $0.1 \%$ tacrolimus ointment showed no significant effect on papulopustular rosacea [29].

Regarding erythema, there was gradual reduction which becomes statistically significant after the second month of treatment with zinc sulfate solution which is comparable to other therapies [28,29].

Zinc sulfate solution had no significant effect on telangiectasia and this is like other modalities mentioned in literature [30].

The present study confirmed the findings in Iraqi study, which showed that oral zinc sulfate was an effective in controlling rosacea lesions [30].

Results of previous studies showed that oral zinc sulfate was effective in controlling rosacea lesions, and side effects were mild and transient [30]. In this study it was found that zinc sulfate solution was simple, effective and with no important side effects, this makes zinc sulfate (especially the solution) superior to other drugs in the treatment of acnerosacea.

Treatment with topical zinc sulfate solution had no important side effects and could be used as topical therapy in mild cases and could be combined with oral therapy like oral zinc sulfate [30], azithromycin and others.

\section{Conclusion}

In conclusion, $5 \%$ zinc solution and $2 \%$ tea lotion were effective in the management of mild to moderate acne rosacea and could be used alone or combined with oral therapy.

\section{Disclosure}

This study was an independent study and not funded by any drug companies.

\section{REFERENCES}

[1] T. Roihu and A. L. Kariniemi, "Demodex Mites in Acne
Rosacea,” Journal of Cutaneous Pathology, Vol. 25, No. 10, 1998, pp. 550-552. http://dx.doi.org/10.1111/j.1600-0560.1998.tb01739.x

[2] K. Kaszuba-Bartkowiak and R. Goś, “The Assessment of Bacterial Flora and Antibiotic-Sensitivity of Bacteria Isolated from Conjunctival Sac, Skin of the Eyelids and Inflammatory Lesions in Patients with Acne Vulgaris and Rosacea,” Przegląd Lekarski, Vol. 64, No. 12, 2007, pp. 991-996.

[3] T. Jansen, U. Kastner, A. Kreuter and P. Altmeyer, "Rosacea-Like Demodicidosis Associated with Aquired Immunodeficiency Syndrome," British Journal of Dermatology, Vol. 144, No. 1, 2001, pp. 139-142. http://dx.doi.org/10.1046/j.1365-2133.2001.03794.x

[4] W. D. James, T. G. Berger and D. M. Elston, "Acne in: Andrews Disease of the Skin, Clinical Dermatology," 10th Edition, WB Sounder Company Philadelphia, 2006, pp. 231-250.

[5] A. E. Rebora, "Helicobacter pylori and Rosacea," Journal of the European Academy of Dermatology and Venereology, Vol. 14, No. 5, 2000, p. 344.

[6] H. Aizawa and M. Niimura, "Oral Spironolactone Therapy in Male Patient with Rosacea,” Journal of Dermatology, Vol. 19, 1992, pp. 293-297.

[7] M. R. Robert, "Vitamines and Trace Element Deficiency and Excess," Harrison's Principle of Internal Medicine, 16th Edition, McGraw-Hill Companies, Inc., New York, 2005, pp. 403-411.

[8] N. Buist and R. Steiner, "Disorder of Metal Metabolism," In: A. G. Campbell and N. Mclntodh, Eds., Churchill Livingstone, Oxford, 1998.

[9] E. F. Rostan, H. V. De Buys, D. L. Madey and S. R. Pinnell, "Evidence Supporting Zinc as an Important Antioxidant for Skin,” International Journal of Dermatology, Vol. 41, No. 9, 2002, pp. 606-615. http://dx.doi.org/10.1046/j.1365-4362.2002.01567.x

[10] K. E. Sharquie and K. K. Al-Azzawi, "Intralesional Therapy of Cutaneous Leishmaniasis with 2\% Zinc Sulfate Solution," Journal of Pan-Arab League of Dermatologists, Vol. 7, No. 2, 1996, pp. 41-49.

[11] K. E. Sharquie and A. A. Al-Nuaimy, "Treatment of Viral Warts by Intralesional Injection of Zinc Sulfate,” Annals of Saudi Medicine, Vol. 22, No. 1-2, 2002, pp. 26-28.

[12] K. E. Sharquie, A. A. Khorsheed and A. A. Al-Nuaimy, "Topical Zinc Sulphate Solution for Treatment of Viral Warts,” Saudi Medical Journal, Vol. 28, 2007, pp. 477 480.

[13] K. E. Sharquie, A. A. Noaimi, S. A. Al-Hashimy and I. F. Al-Tereihi, "Treatment of Tinea Corporis by Topical 10\% Zinc Sulfate Solution,” The Postgraduate Medical Journal, Vol. 12, 2013, pp. 247-250.

[14] K. E. Sharquie, W. S. Al-Dori, I. K. Sharquie and A. A. Al-Nuaimy, "Treatment of Pityriasis Versicolor with Topical 15\% Zinc Sulfate Solution,” 15th Congress of the European Academy of Dermatology and Venereology, 2006.

[15] K. E. Sharquie, R. A. Najim, I. B. Farjou and D. J. Al-Ti- 
mimi, "Oral Zinc Sulphate in the Treatment of Acute $\mathrm{Cu}-$ taneous Leishmaniasis," Clinical and Experimental Dermatology, Vol. 26, 2001, pp. 21-25.

http://dx.doi.org/10.1046/j.1365-2230.2001.00752.x

[16] K. E. Sharquie, R. A. Najim and H. N. Al-Salman, "Oral Zinc Sulphate in the Treatment of Rosacea. A Double Blind Placebo-Controlled Cross-Over Study," International Journal of Dermatology, Vol. 45, No. 7, 2006, pp. 857-861.

[17] K. E. Sharquie, I. A. Al-Turfi and S. M. Sallom, "The Antibacterial Activity of Tea in Vitro and Vivo in Patients with Impetigo Contagiosa,” Journal of Dermatology, Vol. 27, 2000, pp. 706-710.

[18] E. K. Sharquie, I. A. Al-Turfi and W. Al-Shimary, "Treatment of Acne Vulgaris 2\% Topical Tea Lotion," Saudi Medical Journal, Vol. 27, 2006, pp. 83-85.

[19] S. Liao, "The Medicinal Action of Androgens and Green Tea Epigallocatechin Gallate,” Hong Kong Medical Journal, Vol. 7, No. 4, 2001, pp. 369-374.

[20] K. E. Sharquie, A. A. Noaimi and M. M. Al-Salih, “Topical Therapy of Acne Vulgarisusing 2\% Tea Lotion in Comparison with 5\% Zinc Sulphate Solution,” Saudi Medical Journal, Vol. 29, 2008, pp. 1757-1761.

[21] F. Al-Gurairi, M. M. Al-Waiz and K. E. Sharquie, "Oral Zinc Sulphate in the Treatment of Recalcitrant Viral Warts: Randomizd Placebo-Controlled Clinical Trial," British Journal of Dermatology, Vol. 146, No. 3, 2002, pp. 423-431. http://dx.doi.org/10.1046/j.1365-2133.2002.04617.x

[22] O. J. Clermensen and J. Siggaard, "Psoriatic Arthritis Treated with Zinc Sulphate,” British Journal of Dermatology, Vol. 103, No. 4, 1980, pp. 411-415. http://dx.doi.org/10.1111/j.1365-2133.1980.tb07264.x
[23] A. S. Parsad, “Zinc Disorders,” In: J. Ston, Ed., Dermatology, Immunology, and Allergy, C.V. Mosbey \& Co., St Louis, 1985, pp. 759-765.

[24] I. R. Record, "Protection by Zinc against UVA and UVB Induce Cellular and Genomic Damage in Vivo and in Vitro,” Biological Trace Element Research, Vol. 53, No. $1-3,1996$, pp. 19-25. http://dx.doi.org/10.1007/BF02784541

[25] S. K. Katiyar, "Skin Photoprotection by Green Tea: Antioxidant and Immunomodulatory Effects," Current Drug Targets-Immune, Endocrine \& Metabolic Disorders, Vol. 3, 2003, pp. 234-242.

[26] S. K. Katiyar, “Green Tea Polyphenols Treatment to Human Skin Prevent Formation of Ultraviolet Light B-Induced Pyrimidine Dimmers in DNA," Clinical Cancer Research, Vol. 6, No. 10, 2000, pp. 3864-3869.

[27] K. Mutasunaga, T. W. Klein and H. Fridman, "Legionella Pneumophila Replication in Macrophages Inhibited by Selective Immunomodulatory Effect on Cytokine Formation by Epigallcatechingallat a Major from of Tea Catechines," Infection and Immunity, Vol. 69, No. 6, 2001, pp. 3947-3953.

[28] Y. H. Johan, "A Therapeutic Trial in Rosacea of Metronidazole and Azithromycin,” MSc Thesis, Department of Pharmacology, College of Medicine, University of Baghdad, 2004.

[29] J. T. Bamford, B. A. Elliott and I. V. Haller, "Tacrolimus Effect on Rosacea," Journal of the American Academy of Dermatology, Vol. 50, 2004, pp. 107-108.

[30] A. K. Gupta, “Topical Metronidazole for Rosacea,” Skin Therapy Letter, Vol. 7, 2002, pp. 1-3,6. 